\title{
Effects of Met-Enkephalin on GABAergic Spontaneous Miniature IPSPs in Organotypic Slice Cultures of the Rat Hippocampus
}

\author{
Jens C. Rekling \\ Department of Medical Physiology, Division of Neurophysiology, University of Copenhagen, Denmark
}

The action of met-enkephalin on GABAergic spontaneous miniature IPSPs (smIPSPs) was investigated in CA1 neurons from hippocampal slice cultures. In the presence of excitatory amino acid blockers (2,3-dihydroxy-6-nitro-7-sulphamoyl-benzo(F)quinoxaline, DL-2-amino-5-phosphonovaleric acid) and TTX, a continuous high-frequency bombardment of smIPSPs was recorded. The smIPSPs were blocked by the GABA antagonist bicuculline. The occurrence of the smIPSPs was random and their amplitude distribution was skewed toward larger smIPSPs. Met-enkephalin (10-20 $\mu \mathrm{M})$ reversibly reduced the frequency and changed the amplitude distribution of the smIPSPs. The proportion of "large" smIPSPs was reduced, but a loss of "small" smIPSPs also contributed to the reduction in SmIPSP frequency. The selective $\mu$-receptor agonist DAGO mimicked the effect of met-enkephalin and naloxone blocked the effect of DAGO. Hyperpolarization of the neuronal membranes, produced by reducing the extracellular $\mathrm{K}+$ concentration, did not reduce the frequency of the smIPSPs, nor did it block the effect of DAGO. Reduction of the extracellular concentration of $\mathrm{Ca}^{2+} \mathrm{com}-$ bined with an increase in extracellular $\mathrm{Mg}^{2+}$ or the addition of $\mathrm{Cd}^{2+}$ did not reduce the SmIPSP frequency, nor did it block the effect of DAGO.

These results suggest that CA1 pyramidal cells of hippocampal organotypic cultures are tonically inhibited by spontaneous release of GABA, through a release mechanism that is independent of propagated sodium action potentials. Met-enkephalin and DAGO reduce the tonic inhibition by reducing the frequency of the smIPSPs, through a direct action on the presynaptic GABAergic terminals. The effect was probably not mediated by hyperpolarization of the presynaptic membrane or by modulation of presynaptic $\mathrm{Ca}^{2+}$ currents.

[Key words: miniature IPSPs, spontaneous IPSPs, GABAergic IPSPs, met-enkephalin, DAGO, transmitter release]

Spontaneous miniature synaptic potentials, discovered in the neuromuscular junction by Fatt and Katz (1952), have been an important element in quantal analysis, revealing the statistical

\footnotetext{
Received Sept. 2, 1992; revised Oct. 28, 1992; accepted Nov. 10, 1992.

This work was supported by Dir. Ib Henriksens Foundation, Else and Mogens Wedell-Wedellsborgs Foundation, P. Carl Petersen Foundation, Novo's Foundation, the Lundbeck Foundation, and The Danish Medical Research Council (SSF-12-8715). I thank Dr. B. H. Gähwiler and his staff for their help in establishing the organotypic slice culture method in the laboratory.

Correspondence should be addressed to Jens C. Rekling, M.D., Department of Medical Physiology, Division of Neurophysiology, Panum Institute, Blegdamsvej 3C, 2200 Copenhagen $N$, Denmark.

Copyright (c) 1993 Society for Neuroscience $0270-6474 / 93 / 131954-11 \$ 05.00 / 0$
}

nature of synaptic transmission. Spontaneous miniature synaptic potentials can be recorded not only in the neuromuscular junction, but in a variety of central synapses (Brown et al., 1979; Kojima and Takahashi, 1985; Korn et al., 1987). The observation that miniature synaptic potentials in some of these synapses persist when propagated action potentials are blocked by TTX suggests that, in addition to being a phenomenon through which the statistics of transmitter release can be studied, they may be a basic feature of several central synapses, controlling the excitability of the neurons they impinge on.

One of the central synapses giving rise to spontaneous synaptic potentials is the GABAergic inhibitory synapse formed between inhibitory interneurons and pyramidal/granule cells in the hippocampal formation (Collingridge et al., 1984; Edwards et al., 1990; Ropert et al., 1990; Otis et al., 1991). The intense activity of these synapses is not blocked by TTX, demonstrating that action potentials arising in the inhibitory interneurons is not involved in GABA release from the presynaptic terminals. Otis et al. (1991) envisioned that several neuroactive compounds might modulate the tonic inhibition by regulating the spontaneous release of GABA. The study presented here provides such an example, investigating the effect of met-enkephalin on the frequency and amplitude distribution of spontaneous miniature IPSPs (smIPSPs) in organotypic hippocampal slice cultures.

The current understanding of the excitatory action of opioids on neurons in the $\mathrm{CA} 1$ and $\mathrm{CA} 3$ region of the hippocampal formation involves a decrease of GABAergic transmission through a direct, opioid-induced hyperpolarization of the somatic membrane of inhibitory interneurons (Raggenbass et al., 1985; Madison and Nicoll, 1988; Pang and Rose, 1989). The excitatory action is thus a phenomenon secondary to the somatic inhibition of the inhibitory interneurons, a mechanism termed disinhibition. Recently, Lambert et al. (1991) provided evidence of a direct action of opioids on the inhibitory terminals in the area $\mathrm{CA} 1$, showing that DAGO was inhibitory only when applied close to the presynaptic terminals. This key observation inspired the undertaking of the present study. The action of opioids was tested under circumstances where activity in the soma of interneurons did not influence the spontaneous activity in the inhibitory terminals. After the initial submission of this report, Cohen et al. (1992) reported similar actions of an enkephalin analog (DALA) in acutely prepared hippocampal slices.

\section{Materials and Methods}

Cultures. Organotypic slice cultures were prepared according to the roller-tube technique (Gähwiler, 1984). In brief, one or two 400- $\mu \mathrm{m}$-thick hippocampal slices from 1-d-old rats were placed on a cleaned glass coverslip, embedded in citrated chicken plasma (Sigma, lyophilized) 
that was coagulated by addition of a drop of thrombin (Hoffmann-La Roche), 3-6 mg/ml in Gey's medium (GIBCO, GBSS). The slices were cultured in sealed plastic tubes (flat bottom \#1-56758, Nunc), placed in a rotating roller-drum ( 6 or 15 revolutions $/ \mathrm{hr}$ ) at $36.5^{\circ} \mathrm{C}$ in humidified air. The medium was composed of horse serum $(25 \%)$, basal Eagle medium ( $50 \%$ ), and Hanks's balanced salt solution ( $25 \%$; GIBCO). Glutamine ( $1 \mathrm{~mm})$ and extra glucose $(3.6 \mathrm{~mm})$ were added. The cultures were fed once weekly $(0.75 \mathrm{ml}$ medium), and no antimitotics were used. Experiments were done on slices cultured for 21-90 d (mean, $45 \mathrm{~d}$ ).

Recording system. The recording chamber, which was positioned on an inverted microscope, had a volume of $0.9 \mathrm{ml}$ and a temperature of $35.5^{\circ} \mathrm{C}$ and was constantly superfused at a rate of $0.8 \mathrm{ml} / \mathrm{min}$ with oxygenated $\left(95 \% \mathrm{O}_{2}, 5 \% \mathrm{CO}_{2}, \mathrm{pH} 7.40\right)$ Ringer. The basis Ringer solution was composed of $136.3 \mathrm{~mm} \mathrm{NaCl}, 5.4 \mathrm{~mm} \mathrm{KCl}, 18 \mathrm{~mm} \mathrm{NaHCO}$, $0.4 \mathrm{mM} \mathrm{KH}_{2} \mathrm{PO}_{4}, 0.3 \mathrm{~mm} \mathrm{Na}_{2} \mathrm{HPO}_{4}, 0.4 \mathrm{~mm} \mathrm{MgSO}$, $3.3 \mathrm{~mm} \mathrm{CaCl}, 2$ $\mathrm{mM} \mathrm{MgCl}$, and $5.6 \mathrm{~mm}$ glucose. When $\mathrm{Cd}^{2+}$ were added to the Ringer solution $\mathrm{KH}_{2} \mathrm{PO}_{4}$ and $\mathrm{Na}_{2} \mathrm{HPO}_{4}$ was substituted with $\mathrm{KCl}$ and $\mathrm{NaCl}$ to avoid precipitation. Electrodes were pulled from filamented glass tubes (1.5 mm o.d., $0.8 \mathrm{~mm}$ i.d.) and filled with a 1 or $2 \mathrm{M}$ solution of $\mathrm{KCl}$. The electrodes had resistances of between 30 and $60 \mathrm{M} \Omega$. Penetration of pyramidal cells was done by positioning the recording electrode in the CA 1 region of organotypic cultures and "blindly" impaling neurons. The identity of the cells penetrated was based on their characteristic electrophysiology, primarily distinguishing them from CA3 neurons by their ability to fire repetitively and the absence of burst-like firing. A small number of cells were injected with biocytin and stained using the ABC complex procedure (Horikawa and Armstrong, 1988) to confirm their anatomical location within the culture and their pyramidal appearance. Extracellular stimulation was done, using two isolated, $5-\mu \mathrm{m}-$ thick, twisted platinum wires. The unisolated ends of the platinum wires, spaced $50 \mu \mathrm{m}$, were placed in the cultures, and unipolar rectangular pulses lasting $100 \mu \mathrm{sec}$ at voltages of $18-60 \mathrm{~V}$ were applied.

An Axoclamp $2 \mathrm{~A}$ amplifier with a cutoff frequency of $10 \mathrm{kHz}$ was used for the intracellular recordings. The recorded signals were stored on a four-track tape recorder (Racal) with a bandwidth of DC to 1.25 $\mathrm{kHz}$, and the data were low-pass filtered at $1 \mathrm{kHz}$ ( $\mathrm{RC}$ filter) before the computer analysis.

Data analysis and statistics. Off-line analysis was done on a personal computer using commercially available programs (STREAMER, SIGMAPLOT, PEAKFIT, SYSTAT), programs kindly provided by John Dempster, University of Strathclyde (SCAN), and programs developed by the author. The current-clamp recordings were digitized at $5 \mathrm{kHz}$ using a DAS- $16 \mathrm{~F}$ $A / D$ card. To reduce the influence of random noise transients on the peak detection procedure, the digitized data were run through a digital filter (linear smoothing over 11 samples) that gave a reduction in the signal of $-1 \mathrm{~dB}$ at $128 \mathrm{~Hz},-3 \mathrm{~dB}$ at $205 \mathrm{~Hz}$, and $-5 \mathrm{~dB}$ at $258 \mathrm{~Hz}$ (Fig. $1 A$, top and middle traces).

The detection of smIPSPs in the signal was based on the following peak detection procedure. The digitally smoothed signal was differentiated in time frames of $2 \mathrm{msec}$, that is, running calculation of the difference between the $n$th point and $n$th +10 point (Fig. $1 A$, bottom trace). A threshold was set arbitrarily, and upon a threshold crossing in the differentiated data, the program searched for the first negative differentiated data point minus one, since this point must correspond to the peak of a fast rising signal.

The program then found all detected smIPSPs that were (1) not preceded by a smIPSP for a time interval previously measured as the time from peak to baseline and not succeeded by an smIPSP for the same length of time (totally isolated smIPSPs) and (2) not preceded by an smIPSP for a time interval of the time from peak to baseline and not succeeded by an smIPSP for $10 \mathrm{msec}$ (semi-isolated smIPSPs), as indicated in Figure $1 B$. The totally isolated smIPSPs were used to calculate the decay time of the SmIPSPs, and the semi-isolated smIPSPs were used to calculate the mean amplitudes and amplitude distributions of the smIPSPs. The semi-isolated smIPSPs were then sorted manually, rejecting the following types of peaks detected by the program: (1) peaks with no clear shape of a synaptic potential (i.e., a fast rising and a slow falling phase), (2) smIPSPs whose exact peak location in time had been distorted by noise transients in the signal, and (3) smIPSPs riding on top of each other, but not separated by the peak detection procedure. If the percentage of rejected peaks were between $20 \%$ and $30 \%$, the numeric value of the threshold was accepted; if not, the threshold value was changed and the peak detection procedure was performed again until the required rejection percentage had been reached. This iteratively selected threshold level remained constant for the entire analysis. The rather high rejection percentage was chosen to ensure that the smallest
A

\section{Raw data}

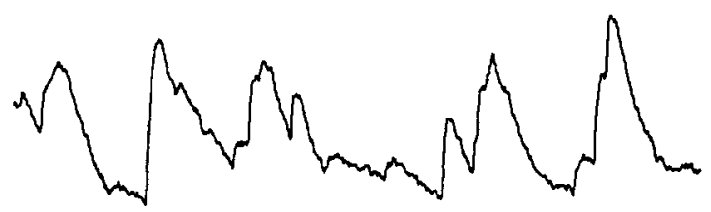

Digitally smoothed data

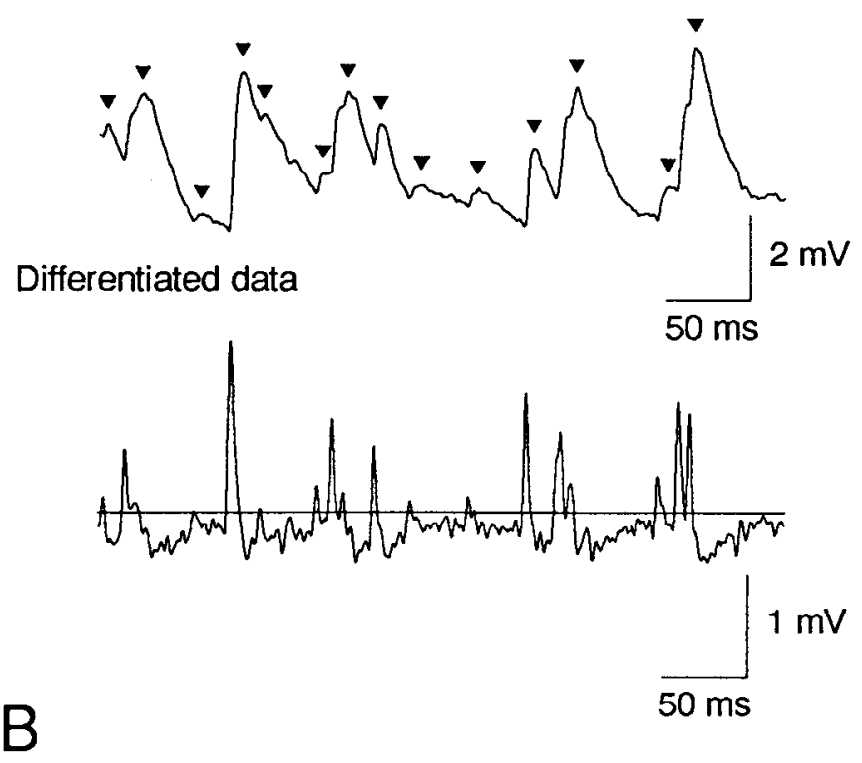

Totally isolated smIPSP

Semi isolated smIPSP
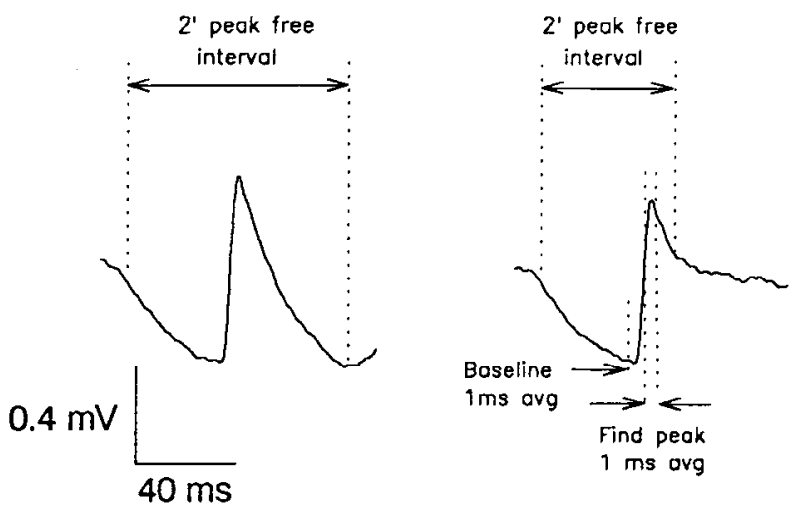

Figure 1. Method for detection and decay and amplitude measurement of smIPSPs. $A$, The top trace is of raw data digitized at $5 \mathrm{kHz}$; the middle trace, digitally smoothed data. $\nabla$ indicates smIPSPs detected on the basis of a threshold crossing and search for nearest negative value in the differentiated data (bottom trace). $B$, The left trace is an average of 107 totally isolated smIPSPs showing the time interval in which the peak detection procedure did not accept a second peak $( \pm 40 \mathrm{msec}$ around the peak); the right trace, an average of 302 semi-isolated smIPSPs showing the second peak-free interval $(-40 \mathrm{mscc},+10 \mathrm{msec}$ in relation to the peak) and the location of the baseline measurement and peak searching interval used to calculate the smIPSP amplitude.

smIPSPs, which this type of experiment could distinguish from noise, were included in the data.

This peak detection procedure has the advantage of being insensitive to voltage offsets in the data as opposed to threshold detection proce- 
dures performed on undifferentiated data. This means that small voltage jumps in the recordings did not affect the detection of a given smIPSP, and smIPSPs riding on the falling phase of other smIPSPs were detected. The latter point was particularly important since the high frequency of the smIPSP meant that a very large percentage of the total number of smIPSPs were riding on top of each other. The peak detection procedure is, however, sensitive to changes in the shape of the rising phase of synaptic potentials. In some experiments the input resistance of the neuron changed during the experiment because of experimental manipulations (e.g., changing $\left[\mathrm{K}^{+}\right]$), thereby changing the time constant of the membrane and consequently the shape of the recorded synaptic potentials. Under these circumstances, the automatic peak detection procedure broke down and the number of SmIPSPs was counted manually in the following way. Eighty sweeps with a duration of $409 \mathrm{msec}$ were randomly pulled out of a $104 \mathrm{sec}$ recording session and displayed on a computer screen. The number of smIPSPs seen on the screen was counted, including those that were riding on top of each other.

Measurements of the smIPSP amplitudes were done on manually sorted semi-isolated smIPSPs using the SCAN program. To perform a reliable measurement of the amplitude of spontaneous and sometimes overlapping smIPSPs, it was necessary to have a baseline unaffected by previous decaying smIPSPs, a rising phase, and peak of the smIPSP, but it was not necessary to have the full length of the falling phase. Drawing out semi-isolated smIPSPs from the data roughly doubled the number of smIPSPs amendable to amplitude measurements compared to the number of totally isolated smIPSPs. The amplitude of an individual smIPSP was then calculated as the difference between the value of a baseline measurement (averaged over $1 \mathrm{msec}$ ) taken $8 \mathrm{msec}$ before the previously found peak and the value of the peak found in a $4 \mathrm{msec}$ window surrounding the previously found peak (averaged over $1 \mathrm{msec}$; Fig. $1 B$ ).

Test statistics used were independent $t$ test on smIPSP frequency data, and Kolmogorov-Smirnov test (KS test) on smIPSP amplitude data (Van der Kloot, 1991). All data are given as mean \pm SEM unless otherwise stated.

Materials. All drugs were applied to the superfusing solution. TTX (tetrodotoxin; Sigma) was used in a concentration of $0.5 \mu \mathrm{M}$; APV (DL2-amino-5-phosphonovaleric acid; Sigma), at $40 \mu \mathrm{M}$; NBQX lithium salt (2,3-dihydroxy-6-nitro-7-sulphamoyl-benzo(F)quinoxaline; a generous gift from NOVO Nordisk A/S), at $20 \mu \mathrm{M}$. (+)-Bicuculline was used at 20-40 $\mu \mathrm{M}$; met-cnkcphalin (mcthioninc-cnkcphalin; Sigma), at 10-20 $\mu \mathrm{M}$; DAGO ([D-Ala ${ }^{2}, N$-Me-Phe $\left.{ }^{4}, \mathrm{Gly}-\mathrm{ol}\right]-$ enkephalin; Peninsula), at $1 \mu \mathrm{M}$; and naloxone- $\mathrm{HCl}$ (Sigma), at $2 \mu \mathrm{M}$.

\section{Results}

\section{Characteristics of SMIPSPS}

Following impalement of a neuron in the CA1 region, the electrophysiological characteristics of the cell were assessed and $\mathrm{KCl}$ from the recording electrode was allowed to diffuse into the cell. This shifted the equilibrium potential for $\mathrm{Cl}^{-}$to a more positive value, thereby improving the ease with which miniature synaptic events could be distinguished from noise. This procedure was based on the observation by Streit et al. (1989), that chloride loading of pyramidal cells from slice cultures shifted the reversal potential of bicuculline-sensitive IPSPs by $20-40 \mathrm{mV}$. A steady hyperpolarizing current injection of $-0.3 \mathrm{nA}$ was applied to the cell during the entire experiment to improve the signal-to-noise ratio further. The superfusing solution was then changed to a solution containing $20 \mu \mathrm{M}$ NBQX and $40 \mu \mathrm{M}$ APV to block spontaneous synaptic transmission carried by excitatory amino acids (Manabe et al., 1992). TTX $(0.5 \mu \mathrm{M})$ was also added to the medium, which completely blocked sodium-dependent action potentials. After an equilibration time of $10 \mathrm{~min}$, spontaneous miniature synaptic potentials were recorded and analyzed. Figure $2 A$ shows the spontaneous synaptic potentials recorded under these conditions. They were positive-going and of different amplitudes and were often riding on top of each other. The triangles indicate the synaptic potentials found by the automatic peak detection procedure. When bicuculline was added to the medium, the spontaneous synaptic potentials almost completely disappeared, leaving a small number of noise transients to be detected (Fig. $2 A$, bottom trace; $20-40 \mu \mathrm{M}, n=$ 6 ). Bascd on blockage by bicuculline and the persistence of the potentials when propagated action potentials had been blocked, the synaptic potentials were classified as $\mathrm{GABA}_{\mathrm{A}}$-mediated smIPSPs. These smIPSPs must arise from spontaneous release of GABA from presynaptic terminals without involvement of propagated sodium action potentials as initially described by Otis et al. (1991).

An average of 156 totally isolated smIPSPs is shown above the top trace in Figure $2 A$. The time to peak was $6.2 \mathrm{msec}$ and the decay of the smIPSP average could be fitted with a single exponential with a time constant of $12 \mathrm{msec}$. Similar measurements from four other cells showed a time to peak ranging from 6.0 to 9.4 msec and a time constant of $10.4-12.6 \mathrm{msec}$.

Figure $2 B$ shows the frequency of the smIPSPs during a period of $4 \mathrm{~min}$. The frequency was stable and averaged at $28.7 \pm 3.9$ smIPSPs/sec (mean \pm SD). An average of the mean smIPSP frequency measurcd in 11 cclls was $27.7 \pm 3.5 \mathrm{smIPSPs} / \mathrm{sec}$, and thus fairly constant from cell to cell. It should be noted that this frequency is somewhat higher than the frequency $(7-14 \mathrm{~Hz}$ ) of spontaneous IPSPs seen in acutely prepared hippocampal slices (Otis et al., 1991).

The random nature of the occurrences of the smIPSPs is illustrated in Figure $2 C$, showing a histogram of the smIPSP intervals. A tolal of 9080 smIPSPs (unsorted, including false smIPSPs) were detected by the peak detection procedure during a period of $5 \mathrm{~min} 14 \mathrm{sec}$. The mean interval was 0.0346 (corresponding to the $28.7 \mathrm{~Hz}$ in Fig. $2 B$ ). The intervals between synaptic events is distributed exponentially if the events occur randomly as described by Fatt and Katz (1952). An exponential fit to all of the data (broken line, Fig. $2 C$ ) did not give a good fit because of a small number of smIPSPs with a very short interval (first bin in the histogram). Sorting the data revealed that this bin represented 175 events with intervals shorter than 6 msec. Since the peak detection procedure only separated smIPSPs with a minimal interval above the time to peak $(6.2$ msec in this data set), these events probably do not represent true smIPSPs, but rather noise transients by chance located very close to true smIPSPs. A fit starting from bin 3 , however, very nicely fitted an exponential function and thus demonstrates the random occurrence of true smIPSPs (solid line, Fig. 2C). In 12 other cells analyzed, the smIPSP intervals also closely followed an exponential distribution.

The amplitude distribution of semi-isolated smIPSPs is shown in Figure $2 D ; 658$ semi-isolated smIPSPs were drawn out of the total population of 9080 detected smIPSPs and their amplitude was measured and plotted in an amplitude histogram. The mean amplitude was $1.01 \mathrm{mV}$, which by inspection of the graph can be seen to be larger than the modal amplitude $(\approx 0.6 \mathrm{mV})$. This difference comes about because of a tail in the distribution toward larger smIPSPs. A Gaussian distribution did not fit the data well ( $r^{2}=0.85$; Fig. $2 D$, broken line), whereas a log-normal distribution (Van der Kloot 1991) gave a better fit $\left(r^{2}=0.96\right.$; Fig. $2 D$, solid line). This skewed distribution toward larger smIPSPs agree with observations of several other miniature synaptic potential distributions in the CNS (Edwards et al., 1990; Ropert et al., 1990; Otis et al., 1991; Kraszewski and Grantyn, 1992). The tail in the amplitude distribution becomes particularly prominent when the smIPSP amplitudes are plotted in a cumulative probability plot (Fig. $2 E$ ). An average of smIPSPs, 


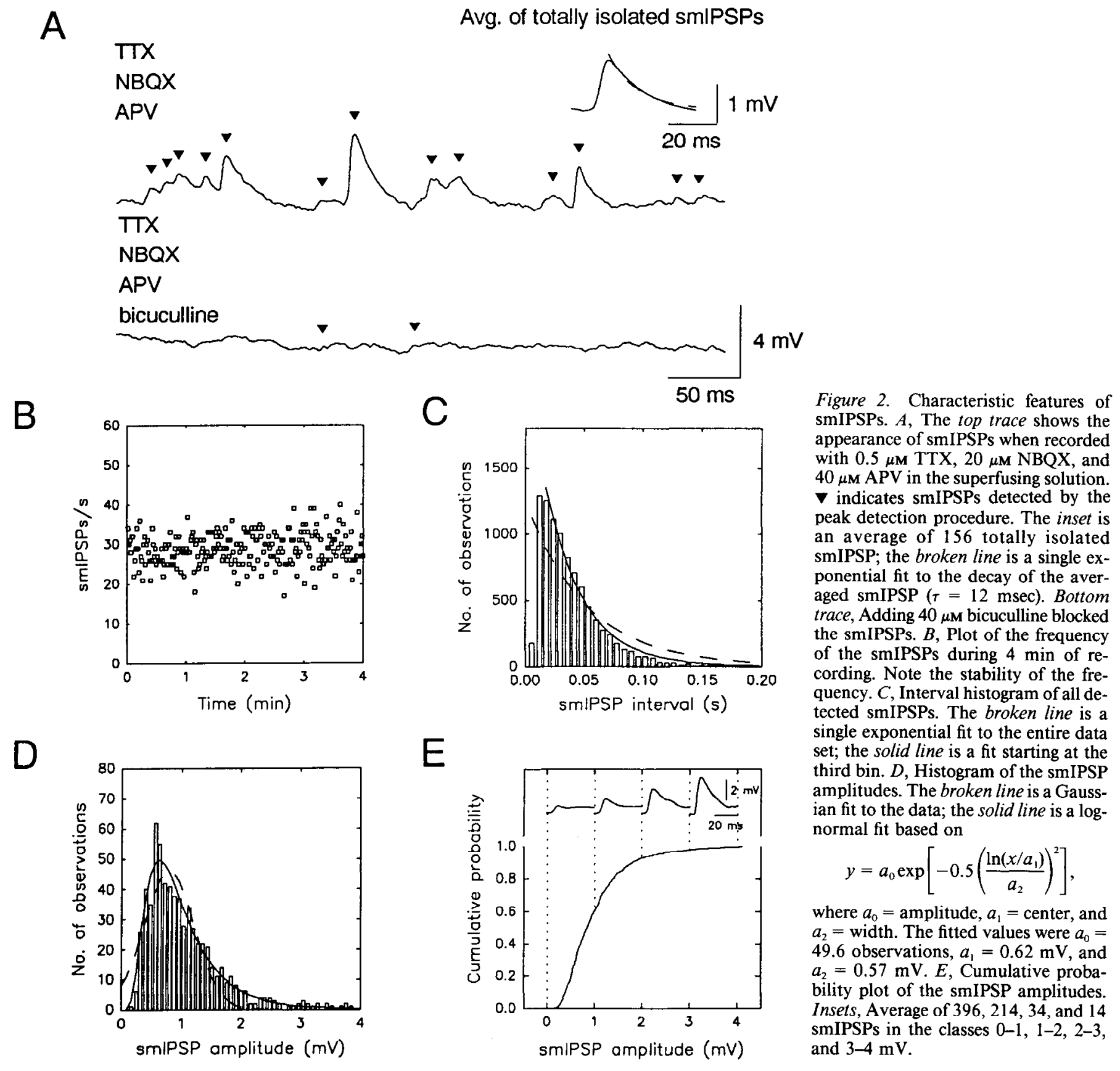

divided into four classes of increasing amplitude $(0-1,1-2,2-$ 3 , and $3-4 \mathrm{mV}$ ), is shown above the cumulative plot. These averages confirm that different amplitude classes of semi-isolated smIPSP indeed had the appearance of a synaptic potential and also show that their time to pcak were almost the same (5.8, 5.6, 5.6, and $5.4 \mathrm{msec}$ ).

\section{Met-enkephalin reduces the frequency of SmIPSPS}

Application of met-enkephalin to the superfusing solution at a concentration of 10-20 $\mu \mathrm{M}$ had no effect on the resting membrane potential or input resistance of the cells $(p>0.05$, paired $t$ test), but significantly reduced the smIPSP frequency in five cells tested. This effect is illustrated in Figure $3 A$. The top trace shows smIPSPs recorded $10 \mathrm{~min}$ into $20 \mu \mathrm{M} \mathrm{NBQX}, 40 \mu \mathrm{M}$ $\mathrm{APV}$, and $0.5 \mu \mathrm{M}$ TTX. The mean smIPSP frequency during 5 min $14 \mathrm{sec}$ of recording was $43.3 \mathrm{~Hz}$. After $5 \mathrm{~min}$ of $20 \mu \mathrm{M}$ metenkephalin, the mean smIPSP frequency was significantly reduced by $24 \%$ to $32.8 \mathrm{~Hz}$ (Fig. $3 A$, middle trace; $p<0.001, t$ test). After $20 \mathrm{~min}$ of wash the smIPSP frequency had returned to the control level reaching $42.9 \mathrm{~Hz}$ ( $p>0.05$, control vs wash). The percentage reduction in the smIPSP frequency in three cells tested with $20 \mu \mathrm{m}$ met-enkephalin was quite variable $(24 \%, 45 \%$, and $74 \%$ ). Met-enkephalin at $10 \mu \mathrm{M}$ in two cells gave a reduction of $33 \%$ and $37 \%$. An average of totally isolated smIPSP in the control, during met-enkephalin, and in the wash showed that the decay of the smIPSPs remained constant (insets, Fig. $3 A$ ). Figure $3 B$ shows another cell in which the mean smIPSP frequency (plotted as smIPSPs per $10 \mathrm{sec}$ ) was monitored during a long recording period before, during, and after application of $20 \mu \mathrm{M}$ met-enkephalin. The reduction in smIPSP frequency ap- 


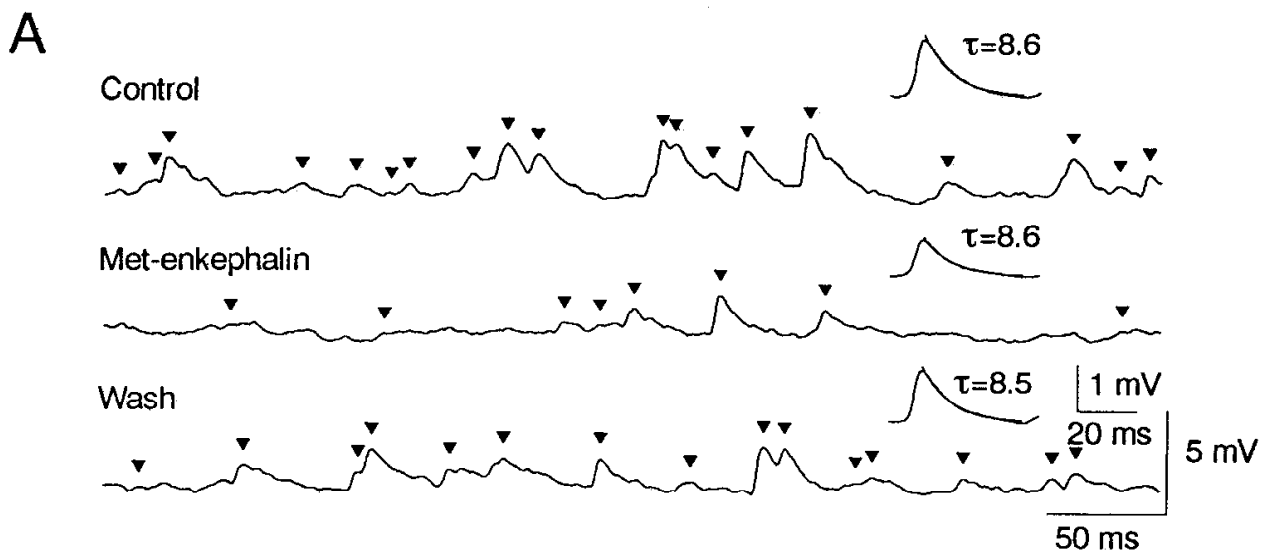

Figure 3. The effect of met-enkephalin on the frequency of smIPSPs. $A$, Sweeps $409 \mathrm{msec}$ long in control, $5 \mathrm{~min}$ into met-enkephalin $(20 \mu \mathrm{M})$, and after $20 \mathrm{~min}$ of wash. Note the reduction of detected smIPSPs $(\nabla)$ during met-enkephalin. Insets, Average of 72, 160, and 58 totally isolated smIPSPs under the conditions indicated. $B$, Plot of the mean smIPSP frequency (cumulated over $10 \mathrm{sec}$ ) before, during $24 \mathrm{~min}$ of $20 \mu \mathrm{M}$ met-enkephalin, and during the wash period. The dotted line is a downward-shifted linear fit to the data during met-enkephalin, illustrating a slight desensitization of the met-enkephalin effect (the frequency increases by 2.8 smIPSPs $/ 10 \mathrm{sec}$ ).

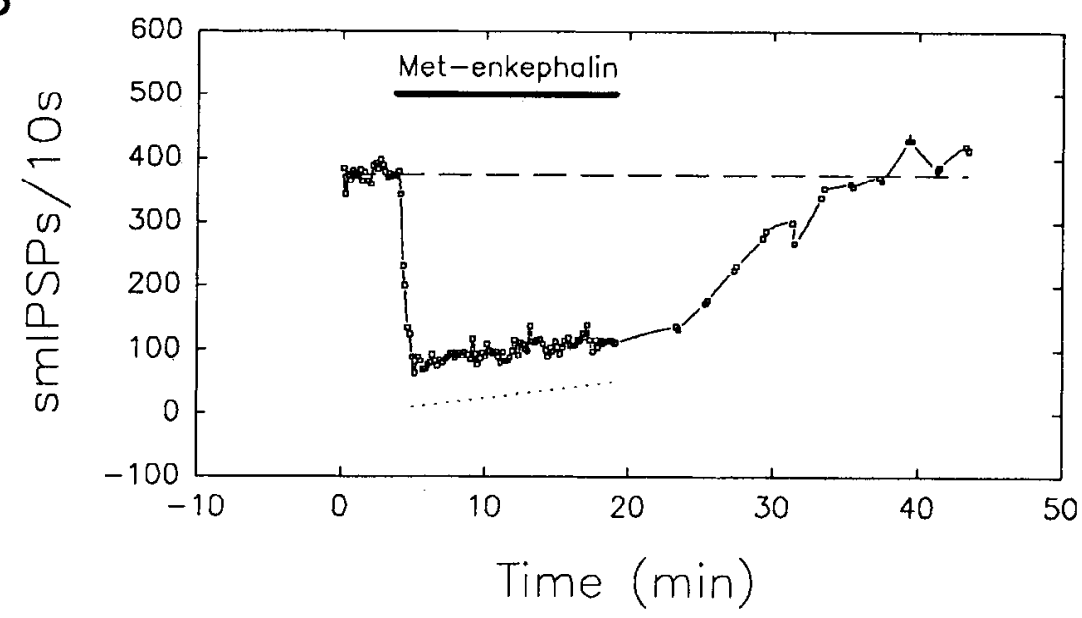

peared quickly after adding met-enkephalin to the bath and reversed slowly in the wash period. During met-enkephalin superfusion there was some desensitization of the effect (broken line is a linear fit of the frequency during met-enkephalin, shifted downward for clarity, Fig. 3B). Interval histograms generated from smIPSPs during met-enkephalin also showed an exponential distribution (but with larger time constants in the fits; data not shown).

\section{Met-enkephalin changed the amplitude distribution of smIPSPs}

Met-enkephalin caused a marked change in the amplitude distribution of the smIPSPs as illustrated in Figure 4. The amplitude distributions shown are plotted as smIPSP amplitude versus relative frequency of each bin (total height of all bins $=1$ ) and a log-normal function has been fitted to the data, as previously described. After $5 \mathrm{~min}$ of $20 \mu \mathrm{M}$ met-enkephalin the relative number of "large" smIPSPs was reduced, which is most clearly seen as a smaller "tail" in the log-normal fit $(p<0.001$, KS test). There was a small change in the modal amplitude of the distributions (control, $0.42 \mathrm{mV}$; met-enkephalin, $0.32 \mathrm{mV}$; wash, $0.39 \mathrm{mV}$ ), based on readings from the log-normal fits. This effect reversed upon wash for $20 \mathrm{~min}$. Although there was a substantial reduction of the number of smIPSPs, giving the distribution its skewed appearance, the distribution in met-enkephalin (or DAGO) was never completely transformed to a true Gaussian. The mean smIPSP amplitude was reduced by $31 \%$, from $0.80 \pm 0.02 \mathrm{mV}$ to $0.55 \pm 0.02 \mathrm{mV}$.

Considering the change in the smIPSPs distribution, the question arises of whether the relative loss of "large" smIPSPs can explain the reduction in the overall frequency in response to met-enkephalin. This question was addressed in Figure 4, $B$ and $C$. In Figure $4 B$ the log-normal fits of the control and metenkephalin (Fig. 4A, left and middle graph) are superimposed. The hatched area represents the relative number of "large" smIPSPs lost during met-enkephalin. The relative number of smIPSPs in this area is $25 \%$ of the total number of smIPSPs. In this particular cell the reduction in the mean smIPSP frequency was $26 \%$ (inset of Fig. $4 B$ ), and thus the loss of "large" smIPSPs could in theory explain the overall reduction in the frequency. Another cell, however, showed a $24 \%$ loss of "large" smIPSPs, whereas the reduction in the mean frequency was much larger (76\%). Thus, in this experiment, there must have been a reduction in the number of smaller smIPSPs (Fig. 4C). This argument, of course, only holds true if the distribution of semi-isolated smIPSPs is identical to the "true" distribution of all smIPSPs.

\section{The selective $\mu$-agonist DAGO mimicked the effect of met-enkephalin}

The observation by Lambert et al. (1991) that DAGO, a selective $\mu$-agonist, depressed evoked IPSPs when applied close to 

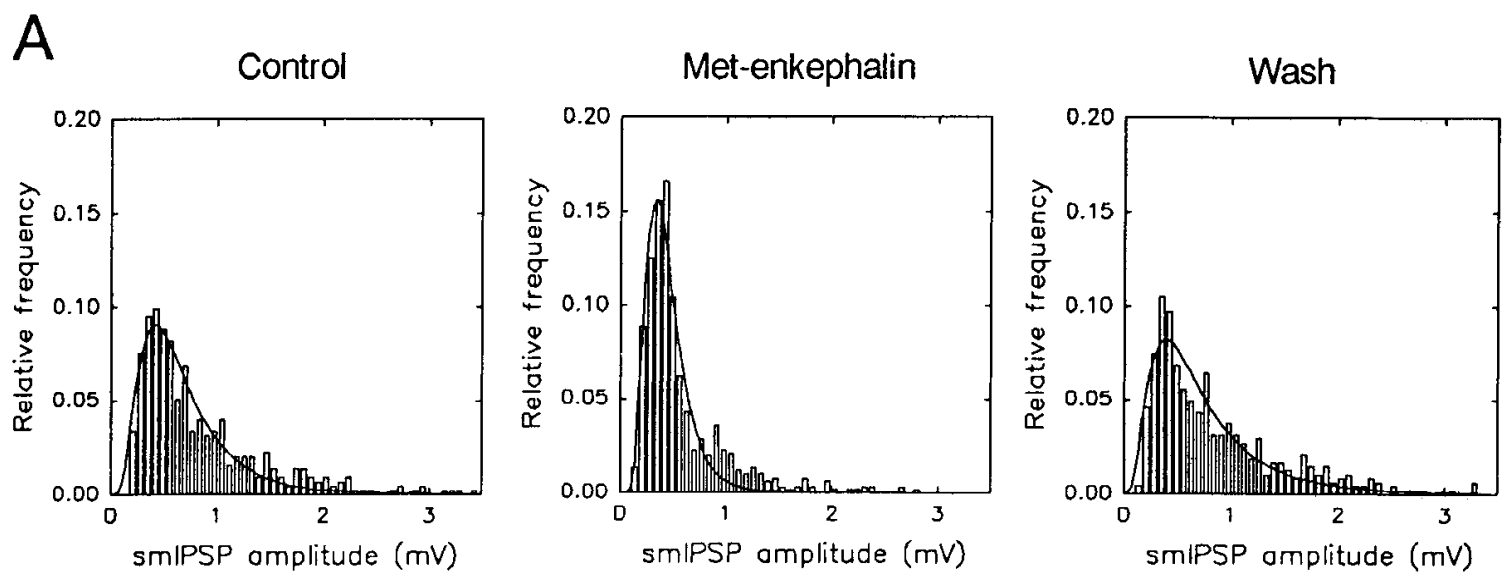

B
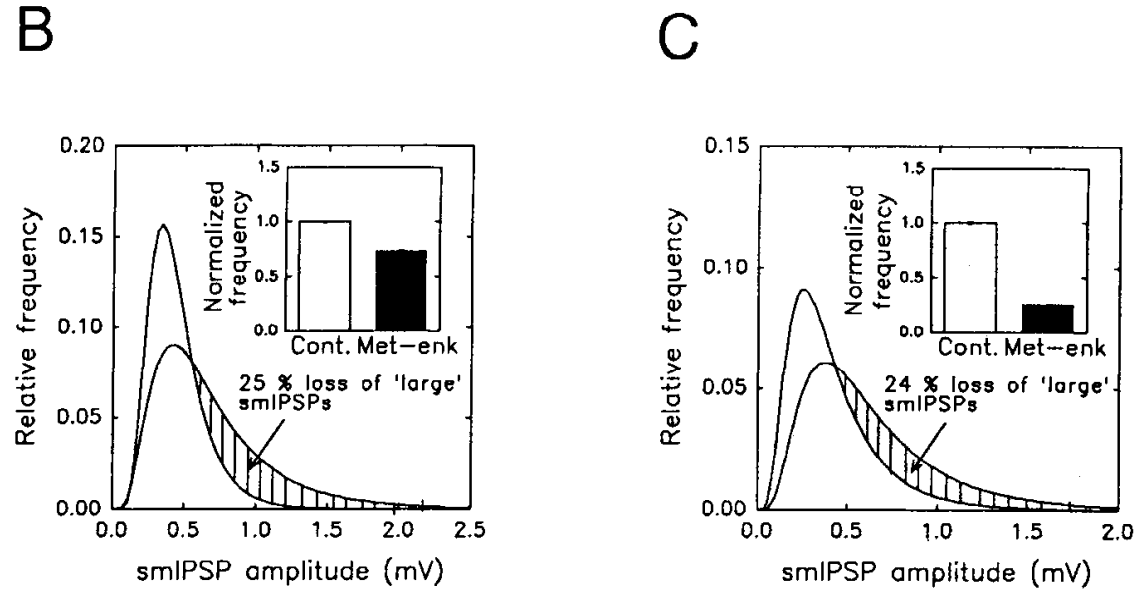

Figure 4. The effect of met-enkephalin on the amplitude distribution of semi-isolated smIPSPs. $A$, Amplitude distributions of semi-isolated smIPSPs in the control, during met-enkephalin $(20 \mu \mathrm{M})$, and after $20 \mathrm{~min}$ of wash. The solid line is a log-normal fit to the data. Note the relative loss of "large" (above $0.55 \mathrm{mV}$ ) smIPSPs during met-enkephalin. B, Superimposed log-normal fits of the data in $A$, left and middle graphs. The hatched area represents the relative loss of smIPSPs above $0.55 \mathrm{mV}$. Inset, The effect of met-enkephalin on the mean (normalized) smIPSP frequency in this cell. $C$, Superimposed log-normal fits of another cell (control and $20 \mu \mathrm{M}$ met-enkephalin). The hatched area represents the relative loss of smIPSPs above $0.44 \mathrm{mV}$. Inset, The effect of met-enkephalin on the mean (normalized) smIPSP frequency.

the presynaptic GABAergic terminals suggested that the presynaptic effect of met-enkephalin seen in this study might also be mediated by activation of $\mu$-receptors. Indeed, $1 \mu \mathrm{M}$ DAGO mimicked the effect of met-enkephalin as shown in Figurc 5 ( $n$ $=9$ ). The traces in Figure $5 A$ are taken in the control, after 5 min of $1 \mu \mathrm{M}$ DAGO, and after $20 \mathrm{~min}$ of wash. DAGO reduced the mean smIPSPs frequency by $29 \%$ (from $21.1 \pm 0.2$ to 14.9 $\pm 0.2 \mathrm{~Hz} ; p<0.001, t$ test), as shown in Figure $5 B$. The mean smIPSP frequency in the wash was above that of the control $(25.9 \pm 0.2 \mathrm{~Hz}, p<0.001)$, a "rebound" phenomenon seen in some but not all cells (including those tested with met-enkephalin). The effect of DAGO could be blocked (two cells) or substantially reduced (one cell) by preincubation of the cultures for $15 \mathrm{~min}$ with $2 \mu_{\mathrm{M}}$ naloxone (Fig. $5 \mathrm{C}$ ), which further suggest the involvement of an opiate $\mu$-receptor. DAGO did not affect the resting membrane potential or input resistance of 11 cells tested $(p>0.05$, paired $t$ test).

\section{No change in smIPSP frequency following hyperpolarization by reducing extracellular $\left[K^{+}\right]$}

A likely mechanism of action of the opioid agonists is a hyperpolarization of the presynaptic GABAergic terminals, since enkephalin has been shown to hyperpolarize the somatic mem- brane of inhibitory interneurons (Madison and Nicoll, 1988). This possibility was investigated in three cells by reducing the extracellular concentration of $\mathrm{K}^{+}$, thereby hyperpolarizing the ncuronal membranes and presumably also the GABAergic terminals. Figure $6 A$ shows the effect of reducing extracellular $\mathrm{K}^{+}$ from $6 \mathrm{~mm}$ to $3 \mathrm{~mm}$ to $0.5 \mathrm{~mm}$. The cultures were superfused with the reduced $\left[\mathrm{K}^{+}\right]_{o}$ Ringer solutions for $12 \mathrm{~min}$ before smIPSPs were recorded. Reducing $\left[\mathrm{K}_{+}\right]_{0}$ from $6 \mathrm{~mm}$ to $3 \mathrm{~mm}$ hyperpolarized the membrane of the pyramidal neuron by 4.5 $\mathrm{mV}$, and reducing the $\left[\mathrm{K}_{+}\right]_{o}$ to $0.5 \mathrm{~mm}$ was followed by a further hyperpolarization of $11.5 \mathrm{mV}$. The input resistance of the pyramidal cell increased from $59 \mathrm{M} \Omega$ in $6 \mathrm{~mm} \mathrm{~K}^{+}$to $89 \mathrm{M} \Omega$ in 3 $\mathrm{mM} \mathrm{K}^{+}$and $133 \mathrm{M} \Omega$ in $0.5 \mathrm{mM} \mathrm{K}^{+}$. The increase in input resistance resulted in an increase in the mean amplitude of the miniature IPSPs as seen on the raw recordings in Figure $6 \mathrm{~A}$. The increase in input resistance and the consequent increase in membrane time constant changed the rate of rise of the smIPSPs. Thus, the automatic peak detection procedure broke down. The frequency of the smIPSPs was therefore counted manually (see Materials and Methods). Figure $6 B$ shows that, although the somatic membrane of the pyramidal cell hyperpolarized approximately $16 \mathrm{mV}$ from $6 \mathrm{~mm}$ to $0.5 \mathrm{mM} \mathrm{K}^{+}$, the mean smIPSP frequency did not change. Adding $1 \mu \mathrm{M}$ DAGO to the $0.5 \mathrm{~mm}$ 

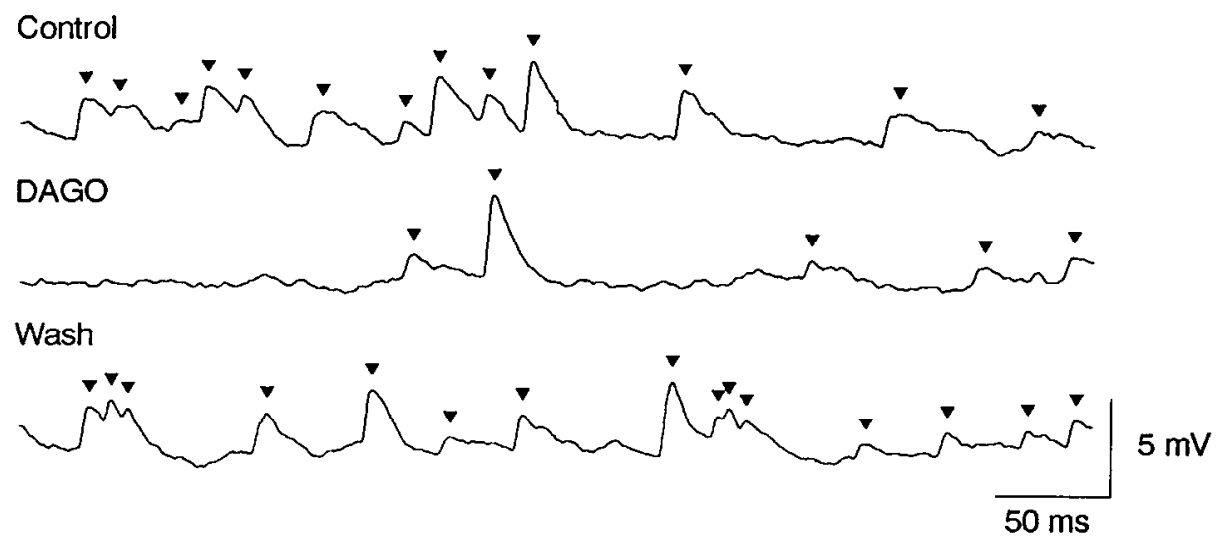

B

Figure 5. The effect of DAGO on the smIPSP frequency and blockage of the effect of DAGO by naloxone. $A$, Traces of smIPSPs in the control, $5 \mathrm{~min}$ into $1 \mu \mathrm{M} \mathrm{DAGO}$, and after $20 \mathrm{~min}$ of wash. $B$, Mean frequency of smIPSPs, based on calculations from $5 \mathrm{~min} 14 \mathrm{sec}$ recordings. Error bars are SEM values (as in all of the following bar diagrams). $C$, Preincubation ( $15 \mathrm{~min}$ ) with $2 \mu \mathrm{M}$ naloxone blocked the effect of $1 \mu \mathrm{M}$ DAGO, whereas DAGO had a potent effect on the smIPSP frequency after $45 \mathrm{~min}$ of wash from naloxone. Mean frequencies are, for control, $25.8 \pm 0.2 \mathrm{~Hz}$; naloxone + DAGO, $26.3 \pm 0.2 \mathrm{~Hz}(p>$ $0.05)$; wash, $26.1 \pm 0.2 \mathrm{~Hz}$; DAGO, $16.0 \pm 0.2 \mathrm{~Hz}(p<0.001, t$ tests $)$.

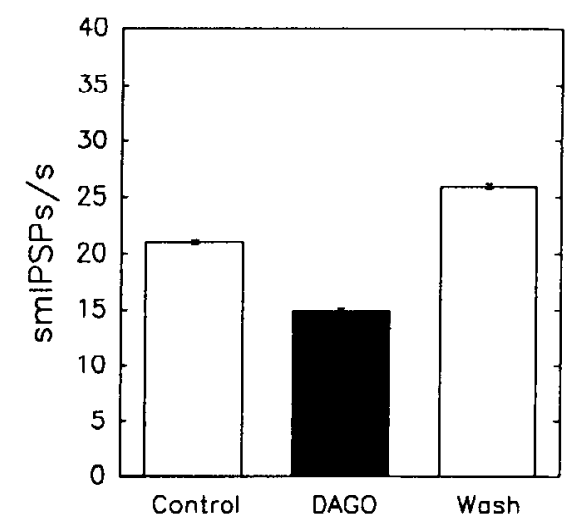

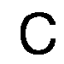

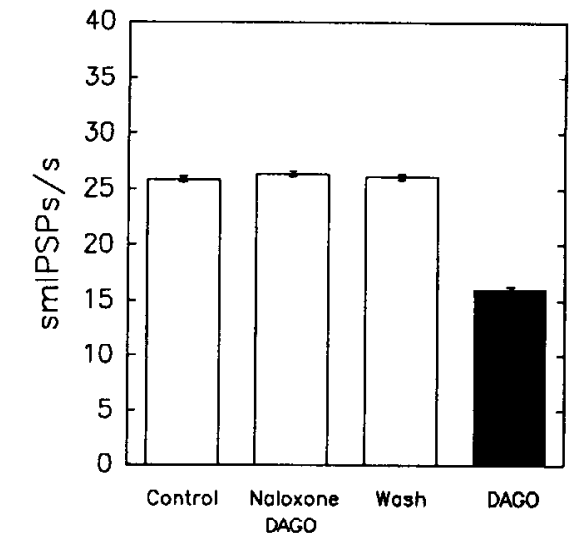

$\left[\mathrm{K}^{+}\right]_{o}$ Ringer still had a potent effect on the mean smIPSP frequency, reducing it by $48 \%$. Assuming that the hyperpolarization of the presynaptic GABAergic terminals was of the same magnitude as the hyperpolarization of the postsynaptic cell, this observation speaks against a mechanism of action of the opioids mediated by a hyperpolarization of the presynaptic GABAergic terminals.

Reduced extracellular $\mathrm{Ca}^{2+}$, increased extracellular $\mathrm{Mg}^{2+}$, or $C d^{2+}$ neither abolished the smIPSPs nor blocked the effect of $D A G O$

Another likely mechanism of action of the opioids is an inhibition of presynaptic voltage-dependent $\mathrm{Ca}^{2+}$ currents. This type of action has primarily been seen during activation of $\delta$ - or $\kappa$-receptors, but recently $\mu$-receptor activation has been shown to inhibit $\mathrm{Ca}^{2+}$ currents in dorsal root ganglion neurons (Schroeder et al., 1991). The possibility of an action on $\mathrm{Ca}^{2+}$ currents was tested by changing the extracellular $\mathrm{Ca}^{2+}$ and $\mathrm{Mg}^{2+}$ concentration or blocking $\mathrm{Ca}^{2+}$ channels with $\mathrm{Cd}^{2+}$. In Figure $7 A$ are shown traces from a control with $3.3 \mathrm{mM} \mathrm{Ca}^{2+}$ and $2.4 \mathrm{~mm}$ $\mathrm{Mg}^{2+}, 10$ min into a Ringer with reduced $\mathrm{Ca}^{2+}$ (nominally 0 $\mathrm{mm})$ and increased $\mathrm{Mg}^{2+}(6 \mathrm{mM})$ and $5 \mathrm{~min}$ into reduced $\mathrm{Ca}^{2+}$, increased $\mathrm{Mg}^{2+}$, and $1 \mu \mathrm{M}$ DAGO. Entering the reduced $\mathrm{Ca}^{2+}$, increased $\mathrm{Mg}^{2+}$ depolarized the cell $13 \mathrm{mV}$ and the input resistance fell $20 \%$ (from $58 \mathrm{M} \Omega$ to $46 \mathrm{M} \Omega$ ), probably due to a change in the charge screening effect. The number of smIPSPs was therefore counted manually and the results are plotted in Figure $7 \mathrm{~B}$. The reduced $\mathrm{Ca}^{2+}$ and increased $\mathrm{Mg}^{2+}$ blocked evoked IPSPs (one cell) and blocked somatically evoked calcium action potentials (one cell, not shown), but surprisingly did not reduce the frequency of smIPSPs. On the contrary, the frequency increased in all three cells tested (33\%, 34\%, and $45 \%$ increase). DAGO $(1 \mu \mathrm{M})$ still had a potent effect of the smIPSP frequency, reducing it by $44 \%$ in the cell shown in Figure 7 . Reducing the $\mathrm{Ca}^{2+}$ concentration in the Ringer to nominally $0 \mathrm{~mm}$, however, does not completely exclude the possibility that some residual $\mathrm{Ca}^{2+}$ remains in the extracellular space. A pharmacological blockade of $\mathrm{Ca}^{2+}$ channels with $100 \mu \mathrm{M} \mathrm{Cd}^{2+}$ was therefore performed (Fig. 8). Five minutes of superfusion with a Ringer containing $100 \mu \mathrm{M} \mathrm{Cd}^{2+}$ completely blocked somatically evoked $\mathrm{Ca}^{2+}$ spikes (three cells) and stimulus-evoked IPSPs (two cells, in the absence of TTX), demonstrating the complete block by $100 \mu \mathrm{M} \mathrm{Cd}^{2+}$ of $\mathrm{Ca}^{2+}$ channels (Fig. $8 \mathrm{~A}$ ). Blocking $\mathrm{Ca}^{2+}$ channels with $\mathrm{Cd}^{2+}$ did not reduce the smIPSP frequency; rather, it increased it (Fig. $8 C ; n=5$ ). Adding $1 \mu \mathrm{M}$ DAGO still had a significant effect, reducing the smIPSP frequency, when $\mathrm{Cd}^{2+}$ was present $(n=4)$. Thus, the smIPSPs are not the result of influx of extracellular $\mathrm{Ca}^{2+}$ into the presynaptic terminals. The persistence of the effect of DAGO under these circumstances indicates that the action of DAGO is not mediated by modulation of presynaptic $\mathrm{Ca}^{2+}$ currents. 
A
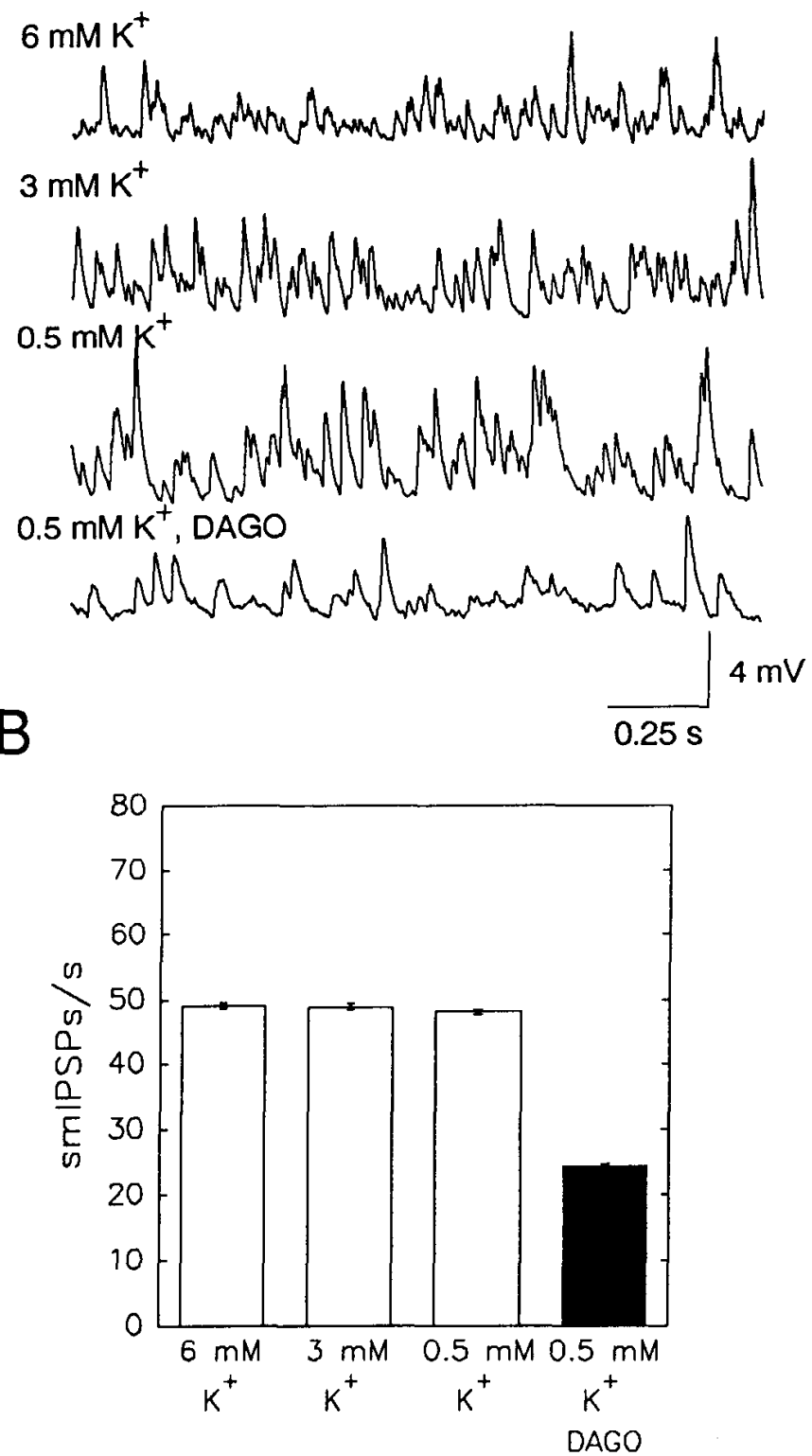

Figure 6. Effect of reduced extracellular $\mathrm{K}^{+}$concentration on the frequency of smIPSPs. $A$, Traces of miniature IPSPs in 6,3 , and $0.5 \mathrm{~mm}$ $\mathrm{K}^{+}$and $0.5 \mathrm{mM} \mathrm{K}^{+}+1 \mu \mathrm{M}$ DAGO. $B$, Plot of manually counted smIPSP frequency at the indicated $\mathrm{K}^{+}$concentrations. Mean frequencies are, for $6 \mathrm{mM} \mathrm{K}^{+}, 49.1 \pm 0.5 \mathrm{~Hz} ; 3 \mathrm{mM} \mathrm{K}+, 48.8 \pm 0.5 \mathrm{~Hz} ; 0.5 \mathrm{mM} \mathrm{K}^{+}, 47.9$ $\pm 0.5 \mathrm{~Hz} ; p>0.05, t$ test. Adding $1 \mu \mathrm{M}$ DAGO to the $0.5 \mathrm{~mm} \mathrm{~K}^{+}$ Ringer significantly reduced the frequency $\left(0.5 \mathrm{~mm} \mathrm{~K} \mathrm{~K}^{+}+1 \mu \mathrm{M}\right.$ DAGO, $24.5 \pm 0.4 \mathrm{~Hz}, p<0.001, t$ test).

\section{Discussion}

This study provides evidence for a new type of disinhibitory action of met-enkephalin in the hippocampus. The results show that met-enkephalin and DAGO modulate the frequency of smIPSPs through an action directly on the inhibitory presynaptic terminals. The study also supports the view that modulation of transmitter release can be mediated by mechanism affecting the release process itself, without or in concert with modulation of prcsynaptic $\mathrm{K}^{+}$or $\mathrm{Ca}^{2+}$ currents (Man-Son-Hing et al., 1989; Shen and Surprenant, 1990).
A

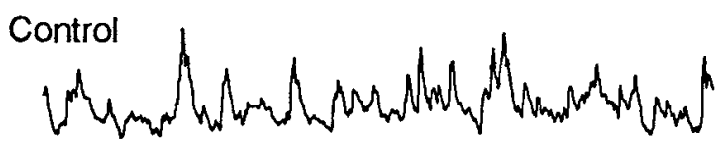

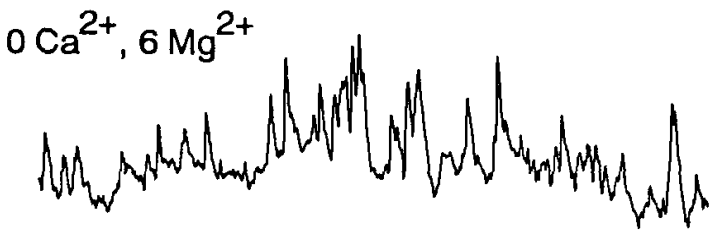

$0 \mathrm{Ca}^{2+}, 6 \mathrm{Mg}^{2+}$, DAGO
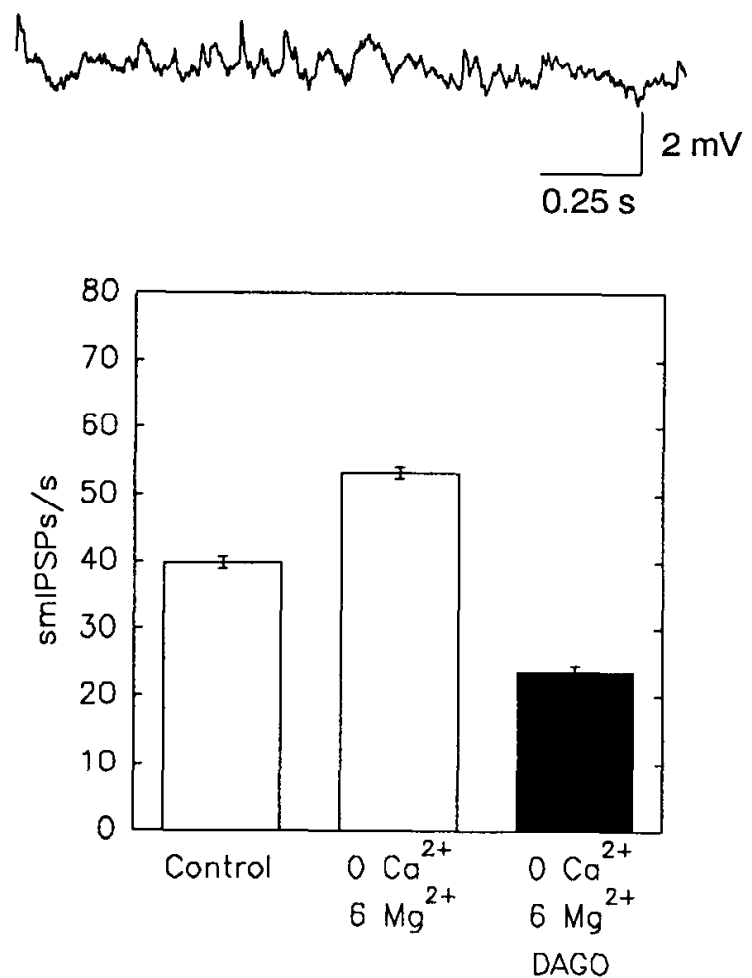

Figure 7. Effect of reduced extracellular $\mathrm{Ca}^{2+}$ and increased extracellular $\mathrm{Mg}^{2+}$ on the frequency of smIPSPs. $A$, Traces of miniature IPSPs in control $\left(3.3 \mathrm{mM} \mathrm{Ca}{ }^{2+}, 2.4 \mathrm{Mg}^{2+}\right) ; 0 \mathrm{mM} \mathrm{Ca}{ }^{2+}, 6 \mathrm{Mg}^{2+}$; and $0 \mathrm{mM}$ $\mathrm{Ca}^{2+}, 6 \mathrm{Mg}^{2+}+1 \mu \mathrm{M}$ DAGO. $B$, Plot of manually counted smIPSP frequency showing an increased frequency in nominally $0 \mathrm{mM} \mathrm{Ca}^{2+}, 6$ $\mathrm{mM} \mathrm{Mg}^{2+}$. Frequencies are, for control, $39.8 \pm 0.8 \mathrm{~Hz} ; 0 \mathrm{mM} \mathrm{Ca}{ }^{2+}, 6$ $\mathrm{mM} \mathrm{Mg}^{2+}, 53.2 \pm 0.8 \mathrm{~Hz} ; p<0.001, t$ test. Adding $1 \mu \mathrm{M}$ DAGO to the $0 \mathrm{mM} \mathrm{Ca}{ }^{2+}, 6 \mathrm{mM} \mathrm{Mg} \mathrm{Mg}^{2+}$ Ringer significantly reduced the frequency $\left(0 \mathrm{mM} \mathrm{Ca}^{2+}, 6 \mathrm{mM} \mathrm{Mg}^{2+}+1 \mu \mathrm{M} \mathrm{DAGO}, 23.8 \pm 0.8 \mathrm{~Hz} ; p<0.001, t\right.$ test).

In the presence of NBQX, APV, and TTX, CAl pyramidal cells from organotypic slice cultures experienced a continuous bombardment of bicuculline-sensitive smIPSPs. Since the concentration of TTX $(0.5 \mu \mathrm{M})$ used in these experiments completely blocked all sodium-dependent action potentials, an effect on smIPSPs can therefore be localized to the presynaptic terminals, the postsynaptic structures, or both, but the soma of inhibitory interneurons was effectively uncoupled. TTX-insensitive synaptic potentials are not seen only in the hippocampus. 
A
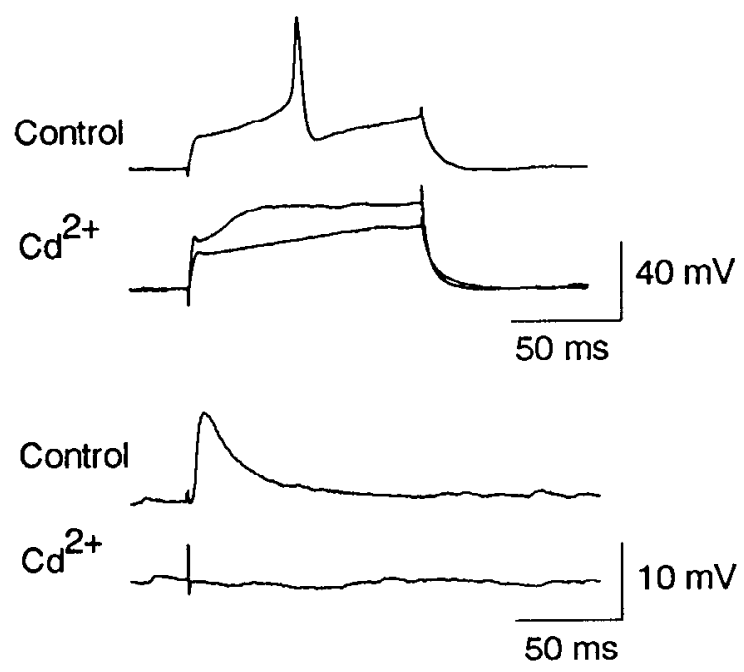

B
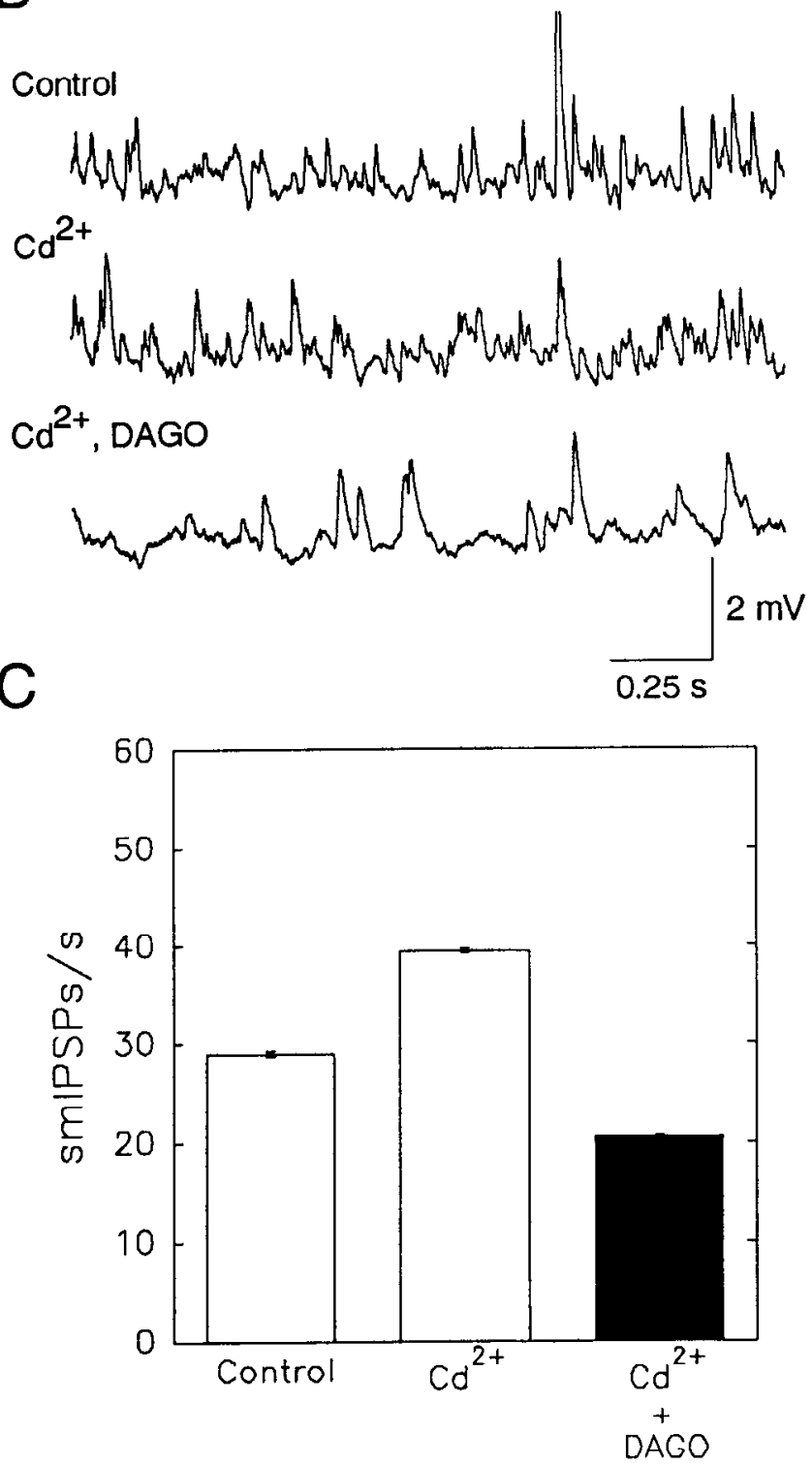

Miniature IPSPs or EPSPs have been recorded from motoneurons and dorsal horn neurons in the spinal cord (Colomo and Erulkar, 1968; Kojima and Takahashi, 1985; Hori et al., 1992). Synaptically connected neurons in dissociated cultures from the hippocampus and superior colliculus also displayed TTX-insensitive, spontaneous synaptic activity (Finch et al., 1990; Kraszewski and Grantyn, 1992; Malgaroli and Tsien, 1992).

The mean smIPSPs frequency $(27.7 \pm 3.5 \mathrm{~Hz})$ recorded in the organotypic slice cultures of this study was higher than the frequency $(7-14 \mathrm{~Hz})$ of spontaneous IPSPs in acutely prepared hippocampal slices (Otis et al., 1991). The cutting procedure in both preparations undoubtedly severed some intrinsic afferents, but a substantial synaptic reorganization probably occurs in the organotypic cultures following the initial cutting (Zimmer and Gähwiler, 1984). The high frequency seen in the cultures may be the result of formation of an abnormally high number of synaptic contacts through sprouting.

The amplitude distribution of the smIPSPs was skewed with a tail of "larger" smIPSPs. This study cannot explain the shape of the distribution. The skewed distribution may be the result of multiquantal release, or it reflects an uneven probability of release of synaptic vesicles packed with a different number of transmitter molecules. The skewed distribution could also be the result of the uneven electrotonic length between the terminals and the recording electrode, but the similar rising times of small and large smIPSPs speak against this idea. Finally, variations in receptor density at different release sites could account for the distribution, or different subtypes of inhibitory interneurons could give rise to different amplitude classes of smIPSPs.

Activation of opioid receptors modulates the release of several neurotransmitters in the CNS. The release of norepinephrine in the rat cortex, hippocampus, and cerebellum is inhibited through activation of opioid $\mu$-receptors (Werling et al., 1987). The release of ACh and 5-HT in the hippocampus is modulated by opioids (Jackisch et al., 1986; Passarelli and Costa, 1989). These effects are thought to be mediated through presynaptic opioid receptors altering the amount of transmitter released. The reduction in evoked GABAergic IPSPs in the hippocampus by opioids (Siggins and Zieglgänsberger, 1981) has not been viewed as a presynaptic modulation of transmitter release, but rather as the result of a disinhibitory mechanism mediated by hyperpolarization of inhibitory interneurons (Madison and Nicoll, 1988). Recently, however, Lambert et al. (1991) presented evidence for an action of opioids directly on the inhibitory terminals reducing evoked IPSPs. The present study confirms a direct action of met-enkephalin and DAGO on the inhibitory presynaptic terminals.

At concentrations of 10-20 $\mu \mathrm{M}$, met-enkephalin reduced the mean smIPSP frequency by $24-74 \%$, and this effect was reversible upon wash. Met-enkephalin had no effect on the mem-

$\leftarrow$

Figure 8. Effect of $\mathrm{Cd}^{2+}$ on calcium spikes, evoked IPSPs, and the frequency of smIPSPs. $A$, Top two traces, $\mathrm{Cd}^{2+}(100 \mu \mathrm{M})$ completely blocked calcium spikes evoked by $1 \mathrm{nA}$ depolarizing current. A $2 \mathrm{nA}$ pulse in $\mathrm{Cd}^{2+}$ did not elicit a $\mathrm{Ca}^{2+}$ spike either. Bottom two traces, $\mathrm{Cd}^{2+}$ $(100 \mu \mathrm{M})$ completely blocked a stimulus evoked IPSP. $B$, Traces of smIPSPs taken in the control, $5 \mathrm{~min}$ into $100 \mu \mathrm{M} \mathrm{Cd} \mathrm{Cd}^{2+}$, and $5 \mathrm{~min}$ into $\mathrm{Cd}^{2+}+1 \mu \mathrm{M}$ DAGO. $C$, Plot of the mean smIPSP frequency in the control, in $100 \mu \mathrm{M} \mathrm{Cd}^{2+}$, and in $\mathrm{Cd}^{2+}+1 \mu \mathrm{M}$ DAGO. Frequencies are $28.9 \pm 0.2 \mathrm{~Hz}, 39.4 \pm 0.2 \mathrm{~Hz}$, and $20.5 \pm 0.2 \mathrm{~Hz}$, respectively; $p<$ $0.001, t$ test. 
brane potential or input resistance measured by the somatic recording electrode or on the decay of the smIPSPs; thus, a postsynaptic action of met-enkephalin was not a likely explanation of the effect. During prolonged exposure of the cultures to met-enkephalin, there was a small desensitization of the effect on the smIPSP frequency. This is in agreement with observations by Gähwiler (1981), who showed that evoked synaptic potentials in organotypic hippocampal cultures developed an acute tolerance to an enkephalin analog. A surprising finding was the change in the smIPSP amplitude distribution. Metenkephalin reversibly changed the distribution into a less skewed one, with a relative loss of "larger" smIPSPs. The modal amplitude of the distribution, however, changed very little, speaking against the notion that the effect of met-enkephalin could be the result of a decrease in the postsynaptic receptor sensitivity. The relative loss of "larger" smIPSPs could not explain the total reduction in the smIPSP frequency. There must also have been a loss of "smaller" smIPSPs. If the skewed distribution of smIPSPs is to be understood in terms of multiquantal release, it can be hypothesized that met-enkephalin reduces the probability of simultaneous release of several quanta to a greater extent than it reduced the probability of release of single quanta. Support for this idea, however, must await experiments that prove the existence of quantal peaks in the amplitude histograms. An alternative explanation to the change in the amplitude distribution could be that certain subtypes of the inhibitory interneurons are insensitive to the opioids.

The selective $\mu$-receptor agonist DAGO mimicked the effect of met-enkephalin, and naloxone blocked the effect of DAGO. This shows that activation of presynaptic $\mu$-receptors is sufficient to mimic the effect of met-enkephalin. It does not, however, exclude the possibility that $\delta$ - or $\kappa$-receptors are involved, and future experiments must show whether activation of the different receptor subtypes have differential effects on the soma and the terminals of inhibitory interneurons.

The mechanism by which DAGO reduced the smIPSP frequency was investigated within the standard conceptual framework of synaptic transmission. In this model, inhibition of transmitter release, at the level of the presynaptic terminal, can be the result of a direct modulation of voltage-sensitive $\mathrm{Ca}^{2+}$ currents, reducing the influx of $\mathrm{Ca}^{2+}$ into the terminal. It can also be mediated by a modulation of $\mathrm{K}^{+}$or $\mathrm{Cl}^{-}$currents, which by nature of hyperpolarization of the presynaptic membrane reduces the influx of $\mathrm{Ca}^{2+}$. The experiments, however, showed that neither of these mechanisms was a likely explanation to the effect of DAGO on smIPSP frequency. Reducing the extracellular $\left[\mathrm{K}^{+}\right]$from $6 \mathrm{~mm}$ to $0.5 \mathrm{~mm}$ hyperpolarized the soma of pyramidal cells $16-19 \mathrm{mV}$ and presumably also hyperpolarized the presynaptic terminals. This procedure, however, had no effect on the smIPSP frequency, nor did the hyperpolarization block the effect of DAGO. The question of whether the smIPSPs were dependent on influx of extracellular $\mathrm{Ca}^{2+}$ was investigated by reducing extracellular $\mathrm{Ca}^{2+}$, increasing $\mathrm{Mg}^{2+}$, or blocking $\mathrm{Ca}^{2+}$ channels with $\mathrm{Cd}^{2+}$. Although evoked synaptic transmission and calcium action potentials in the soma of pyramidal cells were completely blocked by these procedures, the smIPSPs persisted and DAGO had an undiminished effect when applied after the $\mathrm{Ca}^{2+}$ manipulations. This observation is in agreement with previous studies. Collingridge et al. (1984) showed that smIPSPs in the hippocampus persisted in the presence of 0.2 $\mathrm{mM} \mathrm{CdCl}_{2}$. Otis and Mody (1992) showed that low $\mathrm{Ca}^{2+} /$ high $\mathrm{Mg}^{2+}$ or $200 \mu \mathrm{M} \mathrm{CdCl}_{2}$ reduced but did not abolish spontaneous
GABAergic activity in hippocampal slices. Finch et al. (1990) showed that $0 \mathrm{~mm} \mathrm{Ca}^{2+}$ or $\mathrm{Cd}^{2+}(50 \mu \mathrm{M})$ reduced but did not abolish miniature EPSCs in cultured hippocampal neurons. Kojima and Takahashi (1985) also observed the persistence of miniature IPSPs in spinal motoneurons in low $\mathrm{Ca}^{2+} / \mathrm{high} \mathrm{Mg}^{2+}$. A final example of the insensitivity of miniatures to influx of extracellular $\mathrm{Ca}^{2+}$ comes from Dale and Kandel (1990), who reported that 5-HT and FMRFamide have opposite effects on the frequency of miniature EPSPs between cultured sensory neurons and motoneurons from Aplysia. The effects of 5-HT and FMRFamide persisted in $0 \mathrm{Ca}^{2+}$ plus the $\mathrm{Ca}^{2+}$ chelator BAPTA, or when $\mathrm{Cd}^{2+}(1 \mathrm{mM})$ was added, confirming that the modulation of the spontaneous release did not depend on $\mathrm{Ca}^{2+}$ influx. The smIPSPs in this study did not only persist in low $\mathrm{Ca}^{2+} /$ high $\mathrm{Mg}^{2+}$ or $\mathrm{Cd}^{2+}$, the frequency of the smIPSPs increased. This phenomenon was also noted by Kojima and Takahashi (1985), who observed an increase in the frequency of miniature IPSPs in spinal motoneurons when $\mathrm{Ca}^{2+}$ was substituted by $\mathrm{Mn}^{2+}$, another potent $\mathrm{Ca}^{2+}$-blocking agent. In Aplysia, Dale and Kandel (1990) observed a sluw and progressive increase in the frequency of the miniature EPSPs when $\mathrm{Cd}^{2+}$ was added, and they suggested that the phenomenon may be due to blockade of the $\mathrm{Ca}^{2+}-\mathrm{Na}^{+}$exchanger by $\mathrm{Cd}^{2+}$, which could elevate the levels of $\mathrm{Ca}^{2+}$ in the terminals. Thus, a modulation of the influx of extracellular $\mathrm{Ca}^{2+}$ does not appear to be the mechanism of action of the opioids. What, then, could be the mechanism? Met-enkephalin and DAGO could affect the intracellular $\mathrm{Ca}^{2+}$ sequestering machinery, leading to a decrease in the intraterminal $\mathrm{Ca}^{2+}$ concentration available for the relcasc process. Another possibility is a change in synaptic vesicle mobilization. It has been suggested that presynaptic vesicles exist in a releasable pool and a storage pool, and met-enkephalin and DAGO could change the equilibrium between these two pools by affecting the phosphorylation of synaptic vesicle-associated phosphoproteins like synapsin I and II.

The endogenous opioid modulation of the GABAergic smIPSPs must have a profound effect on the integrative properties of pyramidal cells. Inhibitory GABAergic terminals are primarily located on the soma and proximal dendrites of pyramidal cells (Gamrani et al., 1986). A perpetual release of GABA from these terminals must act as a "filter" on synaptic potentials generated in the distal dendrites, and the endogenous opioids can then be viewed as gain setters of this "filter."

\section{References}

Brown TH, Wong RKS, Prince DA (1979) Spontaneous miniature synaptic potentials in hippocampal neurons. Brain Res 177:194-199.

Cohen GA, Doze VA, Madison DV (1992) Opioid inhibition of GABA release from presynaptic terminals of rat hippocampal interneurons. Neuron 9:325-335.

Collingridge GL, Gage PW, Robertson B (1984) Inhibitory post-synaptic currents in rat hippocampal CAl neurones. J Physiol (Lond) 356:55l-564.

Colomo F, Erulkar SD (1968) Miniature synaptic potentials at frog spinal motoneurones in the presence of tetrodotoxin. J Physiol (Lond) 199:205-221.

Dale N, Kandel ER (1990) Facilitatory and inhibitory transmitters modulate spontaneous transmitter release at cultured Aplysia sensorimotor synapses. J Physiol (Lond) 421:203-222.

Edwards FA, Konnerth A, Sakmann B (1990) Quantal analysis of inhibitory synaptic transmission in the dentatc gyrus of rat hippocampal slices: a patch-clamp study. J Physiol (Lond) 430:213-249.

Fatt P, Katz B (1952) Spontaneous subthreshold activity at motor nerve endings. J Physiol (Lond) 117:109-128.

Finch DM, Fisher RS, Jackson MB (1990) Miniature excitatory syn- 
aptic currents in cultured hippocampal neurons. Brain Res 518:257258.

Gähwiler BH (1981) Development of acute tolerance during exposure of hippocampal explants to an opioid peptide. Brain Res 217:196200.

Gähwiler BH (1984) Slice cultures of cerebellar, hippocampal and hypothalamic tissue. Experientia 40:235-308.

Gamrani H, Onteniente B, Seguela P, Geffard M, Calas A (1986) Gamma-aminobutyric acid-immunoreactivity in the rat hippocampus. A light and electron microscopic study with anti-GABA antibodies. Brain Res 364:30-38.

Hori Y, Endo K, Takahashi T (1992) Presynaptic inhibitory action of enkcphalin on excitatory transmission in superficial dorsal horn of rat spinal cord. J Physiol (Lond) 450:673-685.

Horikawa K, Armstrong WE (1988) A versatile means of intracellular labeling: injection of biocytin and its detection with avidin conjugates. J Neurosci Methods 25:1-11.

Jackisch R, Geppert M, Brenner AS, Illes P (1986) Presynaptic opioid receptors modulating acetylcholine release in the hippocampus of the rabbit. Naunyn Schmiedebergs Arch Pharmacol 332:156-162.

Kojima H, Takahashi T (1985) Characterization of miniature inhibitory post-synaptic potentials in rat spinal motoneurones. J Physiol (Lond) 368:627-640.

Korn H, Burnod Y, Faber DS (1987) Spontaneous quantal currents in a central neuron match predictions from binomial analysis of evoked responses. Proc Natl Acad Sci USA 84:5981-5985.

Kraszewski K, Grantyn R (1992) Unitary, quantal and miniature GABA-activated synaptic chloride currents in cultured neurons from the rat superior colliculus. Neuroscience 47:555-570.

Lambert NA, Harrison NK, Teyler TJ (1991) Evidence for $\mu$ opiate receptors on inhibitory terminals in area CA1 of rat hippocampus. Neurosci Lett 124:101-104.

Madison DV, Nicoll RA (1988) Enkephalin hyperpolarizes interneurones in the rat hippocampus. J Physiol (Lond) 398:123-130.

Malgaroli A, Tsien RW (1992) Glutamate-induced long-term potentiation of the frequency of miniature synaptic currents in cultured hippocampal neurons. Nature 357:134-139.

Manabe T, Renner P, Nicoll RA (1992) Postsynaptic contribution to long-term potentiation revealed by the analysis of miniature synaptic currents. Nature 355:50-55.

Man-Son-Hing H, Zoran MJ, Lukowiak K, Haydon PG (1989) A neuromodulator of synaptic transmission acts on the secretory apparatus as well as on ion channels. Nature 341:237-239.
Otis TS, Mody I (1992) Modulation of decay kinetics and frequency of $\mathrm{GABA}_{\mathrm{A}}$ receptor-mediated spontaneous inhibitory postsynaptic currents in hippocampal neurons. Neuroscience 49:13-32.

Otis TS, Staley KJ, Mody I (1991) Perpetual inhibitory activity in mammalian brain slices generated by spontaneous GABA release. Brain Res 545:142-150.

Pang K, Rose GM (1989) Differential effects of methionines-enkephalin on hippocampal pyramidal cells and interneurons. Neuropharmacology 28:1175-1181.

Passarelli F, Costa T (1989) Mu and delta opioid receptors inhibit serotonin release in rat hippocampus. J Pharmacol Exp Ther 248: 299-305.

Raggenbass M, Wuarin JP, Gähwiler BH, Dreifuss JJ (1985) Opposing effects of oxytocin and of a $\mu$-receptor agonistic opioid peptide on the same class of non-pyramidal neurones in rat hippocampus. Brain Res 344:392-396.

Ropert N, Miles R, Korn H (1990) Characteristics of miniature inhibitory postsynaptic currents in CA1 pyramidal neurones of rat hippocampus. J Physiol (Lond) 428:707-722.

Schroeder JE, Fischbach PS, Zheng D, McCleskey EW (1991) Activation of $\mu$ opioid receptors inhibits transient high- and low-threshold $\mathrm{Ca}^{2+}$ currents, but spares a sustained current. Neuron 6:13-20.

Shen KZ, Surprenant A (1990) Mechanisms underlying presynaptic inhibition through alfa2-adrenoceptors in guinea-pig submucosal neurones. J Physiol (Lond) 431:609-628.

Siggins GR, Zieglgänsberger W (1981) Morphine and opioid peptides reduce inhibitory synaptic potentials in hippocampal pyramidal ccll without altering membrane potential. Proc Natl Acad Sci USA 78: 5235-5239.

Streit P, Thompson SM, Gähwiler BH (1989) Anatomical and physiological properties of GABAergic neurotransmission in organotypic slice cultures of rat hippocampus. Eur J Neurosci 1:603-615.

Van der Kloot W (1991) The regulation of quantal size. Prog Neurobiol 36:93-130.

Werling LL, Brown SR, Cox BM (1987) Opioid receptor regulation of the release of norepinephrine in brain. Neuropharmacology 26: 987-996.

Zimmer J, Gähwiler BH (1984) Cellular and connective organization of slice cultures of the rat hippocampus and fascia dentata. J Comp Neurol 228:432-446. 